\title{
Comparação granulométrica com vistas para o entendimento sedimentar em áreas úmidas no Pantanal da Nhecolândia-MS
}

Particle size comparison with objective to understanding sedimentation in region of Nhecolândia in the Pantanal wetlands

Comparación de tamaño de partícula con el propósito de la comprensión de sedimentación en los humedales del Pantanal Nhecolândia-MS

\author{
Paola Vicentini Boni \\ Discente, UFMS, Brasil. \\ paolavicentiniboni@gmail.com \\ Frederico dos Santos Gradella \\ Professor Doutor, UFMS, Brasil. \\ fregradella@yahoo.com.br \\ Hermiliano Felipe Decco \\ Mestre, UFMS, Brasil. \\ herr.decco@gmail.com
}




\section{RESUMO}

O Pantanal é uma área alagável conhecida no mundo, está localizado na da Bacia do Alto Paraguai. A planície pantaneira é uma bacia sedimentar, deprimida e plana caracterizada principalmente por passar por inundações anuais. Este trabalho tem como objetivo comparar duas áreas do Pantanal da Nhecolândia, leste e sudoeste. Realizou-se trabalho de campo para coleta de amostras com trado do tipo holandês, fazendo a descrição de cor com auxílio da tabela de Munsell, textura e umidade. Após, ocorreu a análise granulométrica para avaliar os resultados obtidos elaborando o histograma para verificar a quantidade e tamanhos dos grãos. Como resultado, percebeu-se que as áreas possuem características sutilmente semelhantes, com diferenças na quantidade da espessura dos grãos ao longo do perfil amostrado, evidenciando nesse ponto, as possíveis diferenças entre duas áreas do Pantanal da Nhecolândia.

\section{Palavras-chave: análise granulométrica; geomorfologia; sedimentação.}

\section{ABSTRACT}

The Pantanal is considered a biggest wetland in the world, is located in the Upper Paraguay River Basin. The Pantanal is a sedimentary basin, plain depressed characterized by undergoing annual floods. This study aims to compare two regions of the Pantanal Nhecolândia, eastern and south-west. Fieldwork was conducted to collect samples auger Dutch type, making the color description with the aid of Munsell table, texture and humidity. After was executed to granulometric analysis and preparing a histogram for examined size of the grains. As a result it that two areas are similar characteristics and but different along the profile the grains type, indicating the possible differences between two areas of the Pantanal Nhecolândia.

Keywords: granulometric analysis, geomorphology, sedimentation.

\section{RESUMEN}

El Pantanal es un humedal conocido en el mundo, se encuentra en la Cuenca del Alto Paraguay. El Pantanal es una cuenca sedimentaria, deprimida y plana destacado principalmente por sometidos a inundaciones anuales. Este estudio tiene como objetivo comparar dos áreas del Pantanal Nhecolândia, Este y Suroeste. El trabajo de campo se llevó a cabo para recoger muestras de la barrena de tipo holandés, haciendo la descripción del color con la ayuda de la tabla de Munsell, la textura y la humedad. Después se le ocurrió a análisis granulométrico para evaluar los resultados obtenidos preparar un histograma para comprobar la cantidad y el tamaño de los granos. Como resultado, se observó que las áreas tienen características sutilmente similares, las diferencias en la cantidad del grosor de los granos a lo largo del perfil de la muestra, indicando de ese punto, las posibles diferencias entre dos áreas del Pantanal Nhecolândia.

Palabras clave: análisis granulométrico; geomorfología; sedimentación. 


\section{INTRODUÇÃO}

Dentre as áreas alagáveis (wetlands) mais importantes do mundo é o Pantanal. Devido seu regime sazonal hídrico de extremos, com inundações e secas, permite que apresente mosaicos de paisagem únicos no mundo, que segudo Ab'Sáber (2003) classifica-o como uma área de transição entre os diversos Domínios Morfoclimáticos, como o Amazônico, Cerrado e os Mares de Morros, completado por Adámoli (1986) quando nomeia-o de Complexo do Pantanal, contribuindo para a existência de biodiversidade da área.

As várias ocorrências de mudanças climática e, consecutivamente, mudanças nos regimes hídricos no tempo geológico, deixaram registros no Pantanal, acumulando em sua paisagem formas de relevo que denotam processos truncados de deposição, os quais acarretam e contribuem nos tempos atuais na dinâmica da vegetação e de sistemas lacustres.

As inundações no Pantanal em são partes ocorridas devido a área ser uma depressão e ao mesmo tempo uma extensa planície, a qual ocupa área de aproximadamente $138.183 \mathrm{~km}^{2}$ no Brasil entre os estados de Mato Grosso $\left(48.865 \mathrm{~km}^{2}\right)$ e Mato Grosso do Sul $\left(89.318 \mathrm{~km}^{2}\right)$ segundo Silva e Abdon (1998), localizada no interior da Bacia do Alto Paraguai (BAP), sendo toda suas águas fluviais e de inundações drenadas pelo seu rio tronco que é o Paraguai, com $2.612 \mathrm{~km}$ de extensão, sendo que $1.683 \mathrm{~km}$ estão no Brasil ou nos limites com a Bolívia e o Paraguai (ANA et al., 2004).

Somado a peculiaridade geomorfológica, tem-se também a questão geológica de que o Pantanal está sobre uma bacia sedimentar ativa, que de acordo com Ussami et al. (1999 apud Assine e Soares, 2004) a formação se deu pela reativação tectônica Andina a aproximadamente $2.5 \mathrm{Ma}$. Acredita-se que em alguns pontos da bacia os sedimentos acumulados podem chegar a $500 \mathrm{~m}$ de profundidade, cuja sedimentação foi iniciada no Plioceno. A região com maior profundidade de sedimentos é no interior do leque do Taquari, atingindo mais de $500 \mathrm{~m}$ de profundidade de sedimentos inconsolidados.

Os sedimentos da Formação Pantanal possibilitam a constituição um deposito d'água de grandes proporções, devido a sucessão de sedimentos predominantemente arenosos, ás vezes argilosos, inconsolidados, e permeáveis (ADAMOLI, 1986)

A compartimentação geomorfológica da BAP realizada por Franco e Pinheiro (1982) define os limites do Pantanal como uma extensa superfície de topografia bastante plana com áreas que frequentemente estão sujeitas a inundações, cuja rede de drenagem é comandada pelo rio Paraguai. As inundações são uma peculiaridade da região, a qual passa por alagamentos anuais, sejam elas por inundação de rios ou pela elevação do lençol freático ao longo das planícies.

Alguns pesquisadores dividem a área, criando então, os Pantanais, como por exemplo Franco e Pinheiro (1992), que em sua subdivisão tem-se o Pantanal do Taquari, que é o sistema deposicional do leque do Taquari com aproximadamente $250 \mathrm{~km}$ de diâmetro. A porção sul do leque é chamado regionalmente de Nhecolândia, com aproximadamente $24.737 \mathrm{~km}^{2}$ de área.

A Nhecolândia é internacionalmente conhecida por apresentar inúmera lagoas, sendo algumas dela chamadas de salinas, que segundo Sakamoto et al. (1996) apresentam pH elevado entre 9,0 e 9,8 podendo muitas vezes chegar a 10 e 11, e são ricas em sódio e potássio. Além das salinas, a área também apresenta em sua morfologia do relevo as baías (lagoas de água doce), cordilheira (elevações com densa vegetação), vazantes (amplas planícies de encharcamento sujeitas a fluxo d'água) e corixos (feições erosivas sujeitas a fluxo d'água) (Franco e Pinheiro, 1982; Gradella, 2012). 
Diversos autores já discutiram sobre a formação das lagoas de água salobra, uma delas é a de Almeida (1945) apresenta uma das primeiras teorias da formação, dizendo que ocorreu retrabalhamento eólico na região das lagoas, visto através de vestígios das características granulométricas. Corroborando com a teoria do retrabalhandomento eólico, Tricart (1982) também atribui a modelagem das lagoas derivadas de energia eólica, principalmente na parte distal do leque, por conter sedimentos mais finos que podem ser retrabalhados com mais facilidade por energia eólica. Desse modo Soares et al. (2003) utilizando análises das características granulométricas e morfoscópicas que a hipótese é provável, pois o material é fino e bem selecionado.

Diante dos expostos, obter mais conhecimento da Nhecolândia permitirá colaborar com futuras ações, pois os registros de paleoindicadores de mudanças climáticas, no caso as geoformas e a características das águas das salinas estão presentes apenas na porção SW, enquanto que no restante elas são inexistentes, causando indagações sobre a evolução não somente para essa área, mas também para o Pantanal como um todo.

\section{OBJETIVOS}

Comparação das características granulométricas das unidades geomórficas de uma lagoa salina e uma área úmida sem presença de lagoas no Pantanal da Nhecolândia.

\section{METODOLOGIA/MÉTODO DE ANÁLISE}

Inicialmente realizou-se o levantamento bibliográfico acerca da Nhecolândia para definir as áreas que seriam analisadas. Após a definição, foi-se a campo em dois períodos (21/09/2015 a 26/09/2015 e 24/10/2015 a 27/10/2015, ambos secos) para coletar amostras que se localizam em duas áreas com características diferentes, porém, tendo elas como semelhanças o fato de estarem próximas a ambientes úmidos.

Os levantamentos de campo foram realizados em: área 1 (A1), porção SW com coordenada $19^{\circ}$ $13^{\prime} 39^{\prime \prime} \mathrm{S}$ e $56^{\circ} 57^{\prime} 00^{\prime \prime} \mathrm{W}$, onde estão presentes as lagoas salinas. Área 2 (A2), porção E com coordenada $18^{\circ} 55^{\prime} 32^{\prime \prime} \mathrm{S}$ e $55^{\circ} 44^{\prime} 58^{\prime \prime} \mathrm{W}$, área onde não há lagoas (Figura 1).

A A1 é no entorno de uma lagoa salina, composta cordão arenoso sem cobertura vegetal e que alaga por elevação do nível da água da lagoa, e está topograficamente entre a parte mais baixa da lagoa e a elevação da cordilheira. A A2 é uma área com vegetação rasteira, próximo encontra-se uma área úmida, com uma leve depressão acumulando água, mas que sofre alagamentos na época da cheia, porém não é área com dinâmica lagunar. Importante ressaltar que essa área não possui estudos prévios. 
Figura 1. Localização da Nhecolândia e dos pontos amostrados.

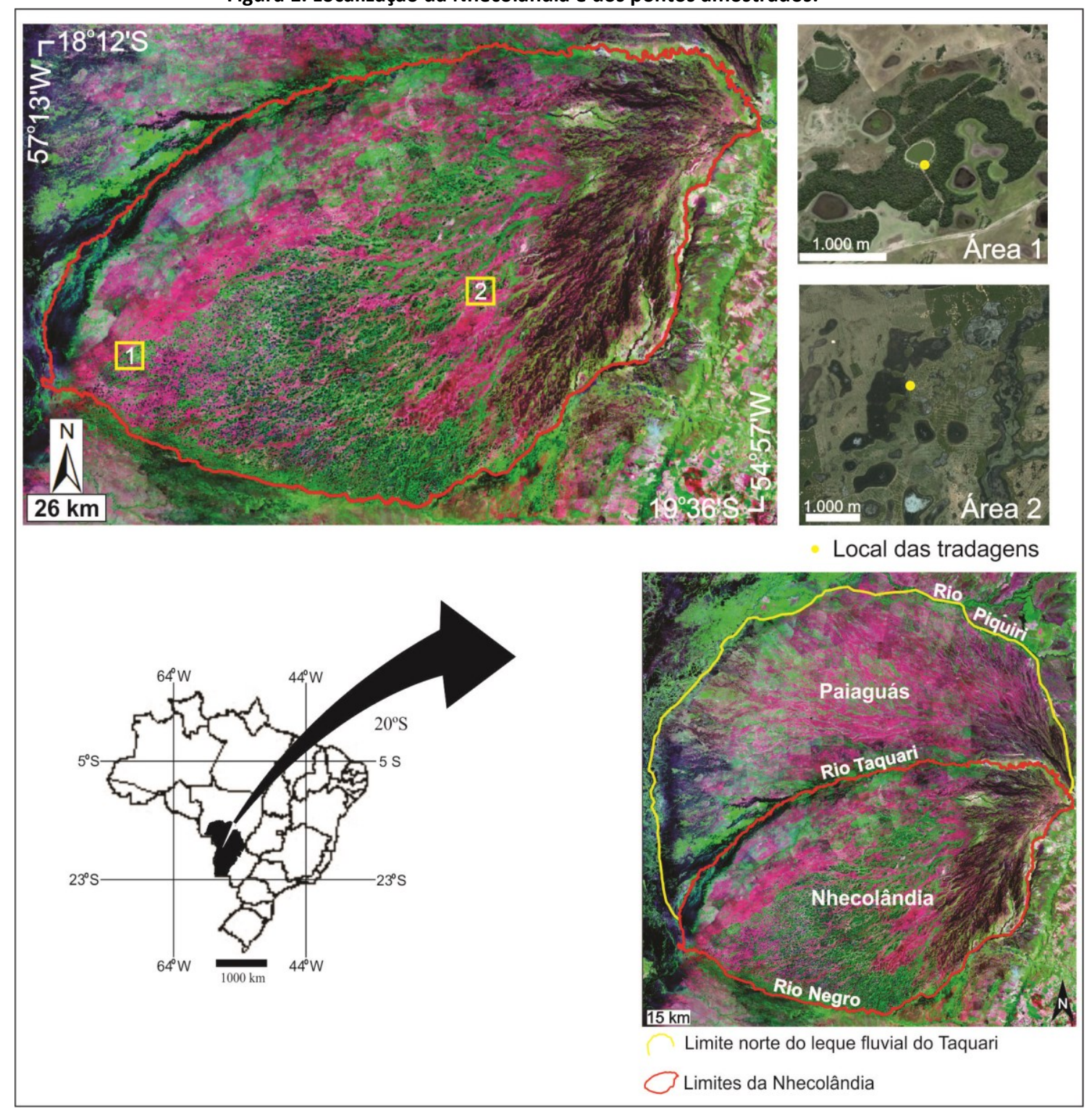

Fonte: Imagens Geocover (2000) e Google Earth.

Para coleta das amostras, utilizou-se o trado tipo holandês para coletar amostras, tabela de Munsell para identificar a cor das amostras, fitas métricas para medir a profundidade das tradagens, sacos plásticos para o armazenamento e GPS para a localização dos pontos. Durante as tradagens analisou-se cor, textura e umidade de cada amostra coletada.

Em laboratório realizou-se a análise granulométrica para caracterizar o tamanho e a distribuição dos grãos de cada amostra. Segundo Dias (2004) assim é possível definir as dimensões pelo peso ou volume dos grãos.

A análise granulométrica exige que as amostras sejam preparadas, para isso utilizou-se a TFSA (terra fina seca ao ar). Após secas, procedeu-se com o destorroamento, separação da quantidade utilizada e pesagem em uma balança de precisão. Por fim, as amostras passaram por peneiramento em agitador de análise granulométrica. As peneiras com malhas de aberturas: $2 \mathrm{~mm}, 1 \mathrm{~mm}, 0,5 \mathrm{~mm}, 0,250 \mathrm{~mm}, 0,125 \mathrm{~mm}, 0,062 \mathrm{~mm}$ e 0,053 $\mathrm{mm}$. 
Desse modo, separaram-se os grânulos em areia muito grossa, areia grossa, areia média, areia fina, areia muito fina, silte e argila. Essa classificação granulométrica foi baseada na proposta de Wentworth (SUGUIO, 1980).

Os dados obtidos em campo foram organizados e tabulados e, para melhor analisar e interpretar os resultados obtidos com a análise granulometrica, realizou-se a elaboração de gráficos, sendo esses do tipo histograma.

\section{RESULTADOS}

As análises granulométricas realizadas na A1 (Figura 2), foram realizadas a partir da coleta de 6 amostras, atingindo a profundidade de $180 \mathrm{~cm}$.

Figura 2. Foto do local da tradagem da área 1.

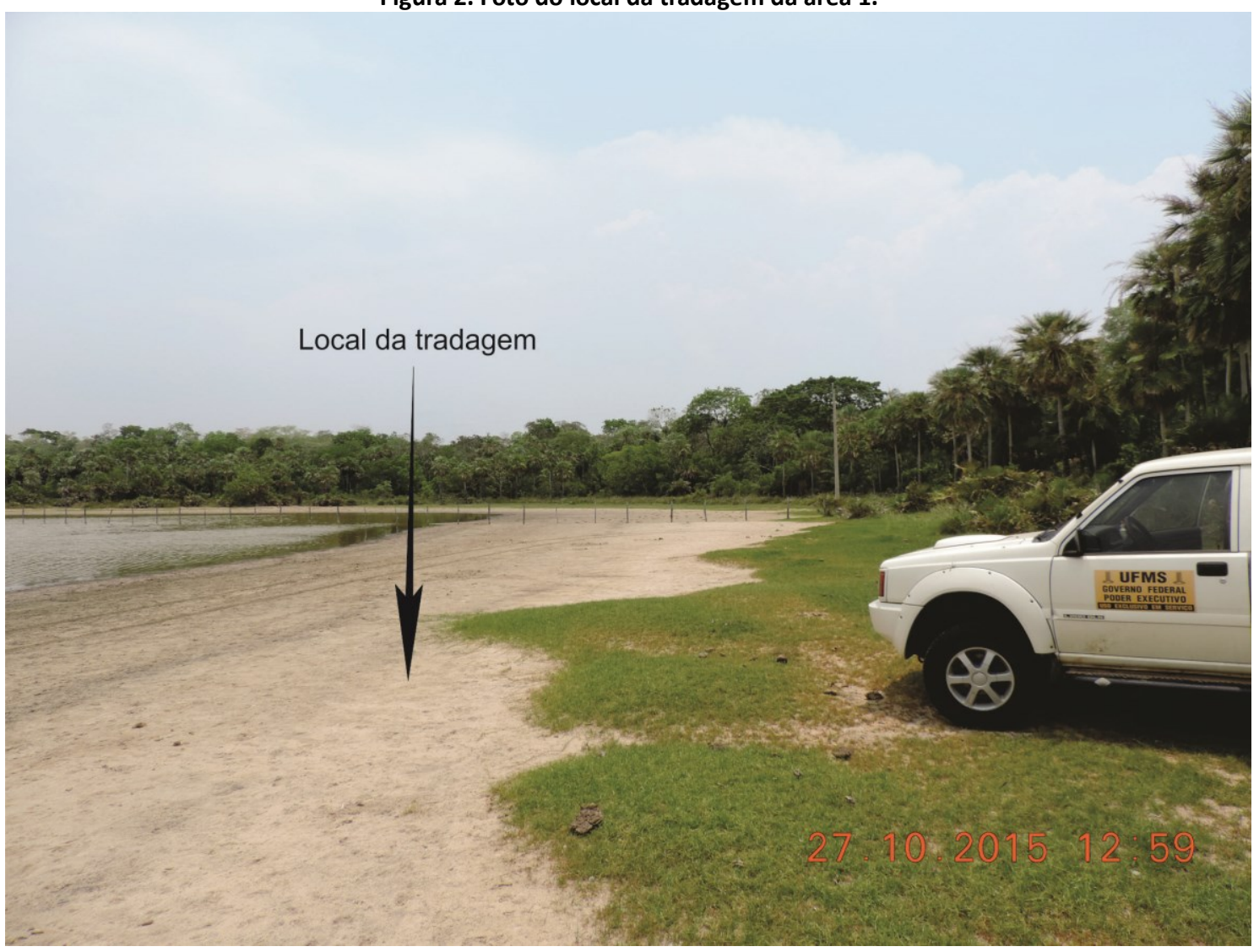

Fonte: Próprio autor (2015).

Na profundidade 0 a $20 \mathrm{~cm}$ possui coloração escura (10 YR 5/2), com veios mais claro que amostra apresenta uma umidade considerável.

De 20 a $40 \mathrm{~cm}$ a cor continua a mesma (10 YR 5/2), assim como a umidade, ocorre 0 aparecimento de material concrecionado com diâmetro pequeno.

Na profundidade de 40 a $60 \mathrm{~cm}$, não ocorre alteração na cor (10 YR 5/2), a umidade aumenta, encontra-se o material concrecionado e alguns veios escurecidos (10 YR 3/2) aparentemente é resquícios de matéria orgânica.

Em 60 a $80 \mathrm{~cm}$, a cor permanece a mesma (10 YR 5/2) ocorre uma transição, mosqueando assim os veios escurecidos (10 YR 3/2) com predominância no final da amostra, a umidade e o material concrecionado permanece. 
Na profundidade 80 a $100 \mathrm{~cm}$, não ocorre alteração na cor (10 YR 5/2), alterando assim a umidade que aumenta significativamente, ocasionando o escurecimento da cor predominante percebe-se que não há presença de veios escurecidos e material concrecionado.

De 100 a $120 \mathrm{~cm}$, a cor permanece a mesma (10 YR 5/2) volta aparecer os veios escuros (10 YR $3 / 2$ ) em menor quantidade, sem presença de concreções e encontra-se água livre.

$\mathrm{Na}$ amostra 120 a $140 \mathrm{~cm}$ ocorre a transição da cor escura (10 YR 5/2) para a cor esverdeada (Gley 1 4/5GY) no final da amostra, não havia muita consciência devido estar com a umidade elevada.

Na profundidade 140 a $160 \mathrm{~cm}$ encontra a predominância da cor esverdeada (Gley 1 4/5GY), percebe-se a presença da pegajosidade na amostra e amostra encontra-se mais úmida quando comparada as anteriores.

E na amostra de 160 a 180 percebe-se presença quase total da cor esverdeada (Gley 1 4/5GY), com muita pegajosidade e umidade elevada.

Percebe-se que todas as profundidades havia predominância da mesma cor, com pequenas alterações sendo os veios escurecidos. Assim, a cor é influenciada pela umidade da lagoa salina que encontra-se a $3 \mathrm{~m}$ do local da tradagem. A cor esverdeada é encontrada nas maiorias das lagoas salinas da Nhecolândia, segundo Rezende Filho (2006) a camada verde é resultado de uma alta variabilidade geoquímica nessas unidades e a existência de um solo mineralizado com uma organização particular.

No Histograma (Figura 3) percebe-se maior concentração dos grãos em 0,125 mm (areia fina) com $60 \%$, ou seja, a maior parte do peso total das amostras encontra-se nesse diâmetro. No gráfico nota-se que a amostra mais próxima da superfície $(0-20 \mathrm{~cm})$ e a amostra de maior profundidade $(160-180 \mathrm{~cm})$, local encontrado o material esverdeado possuem as maiores quantidades de sedimentos muito finos. Segunda maior parte dos grãos encontra-se em 0,062 $\mathrm{mm}$, areia muita fina, aproximadamente $30 \%$. Os $10 \%$ restantes estão divididos entre os outros diâmetros.

Figura 3. Histograma da área 1.

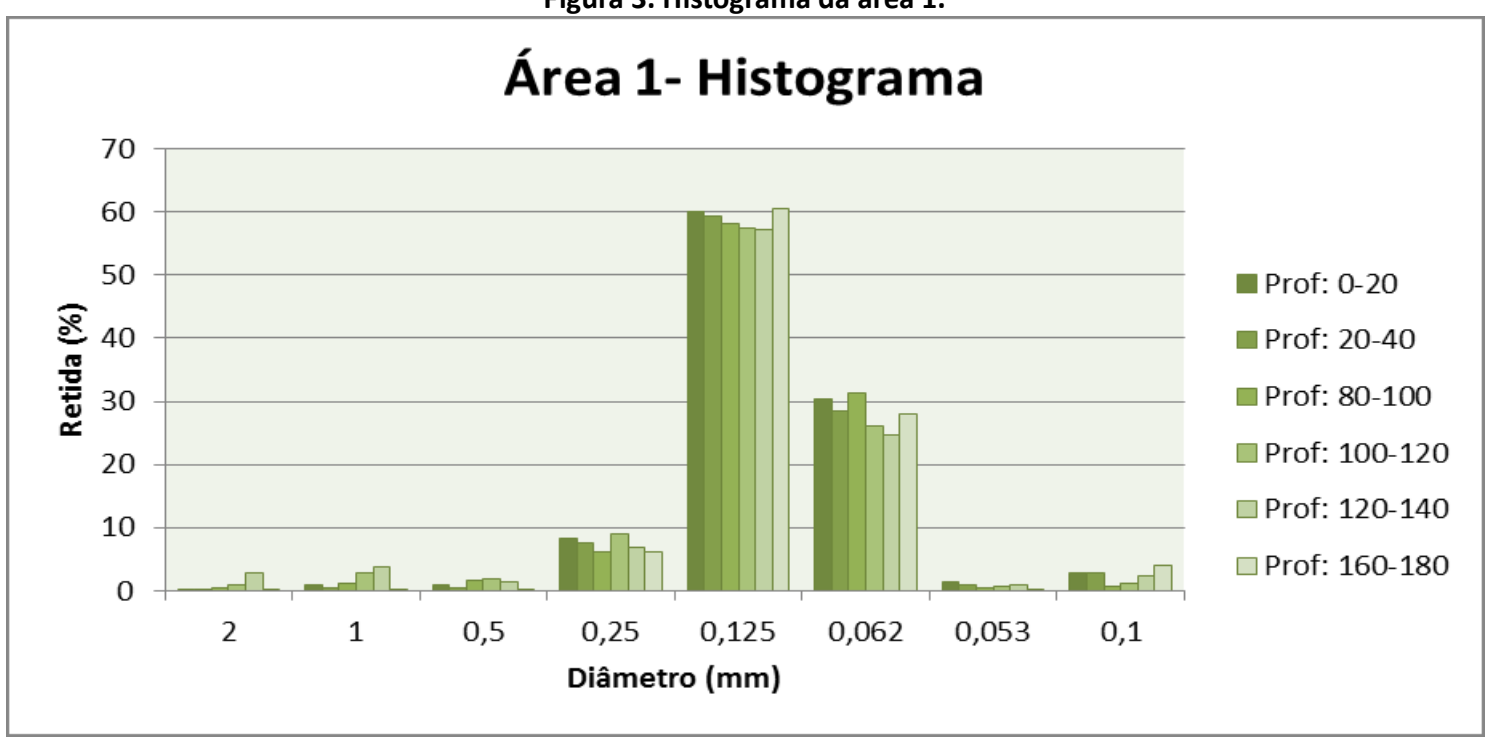

Fonte: Próprio autor (2016).

Em A2 (Figura 4), realizou-se a coleta de amostras até a profundidade de $180 \mathrm{~cm}$, porém, com apenas 4 amostras, devido haver homogeneidade nas amostras. 
Figura 4. Foto do local da tradagem da área 2.

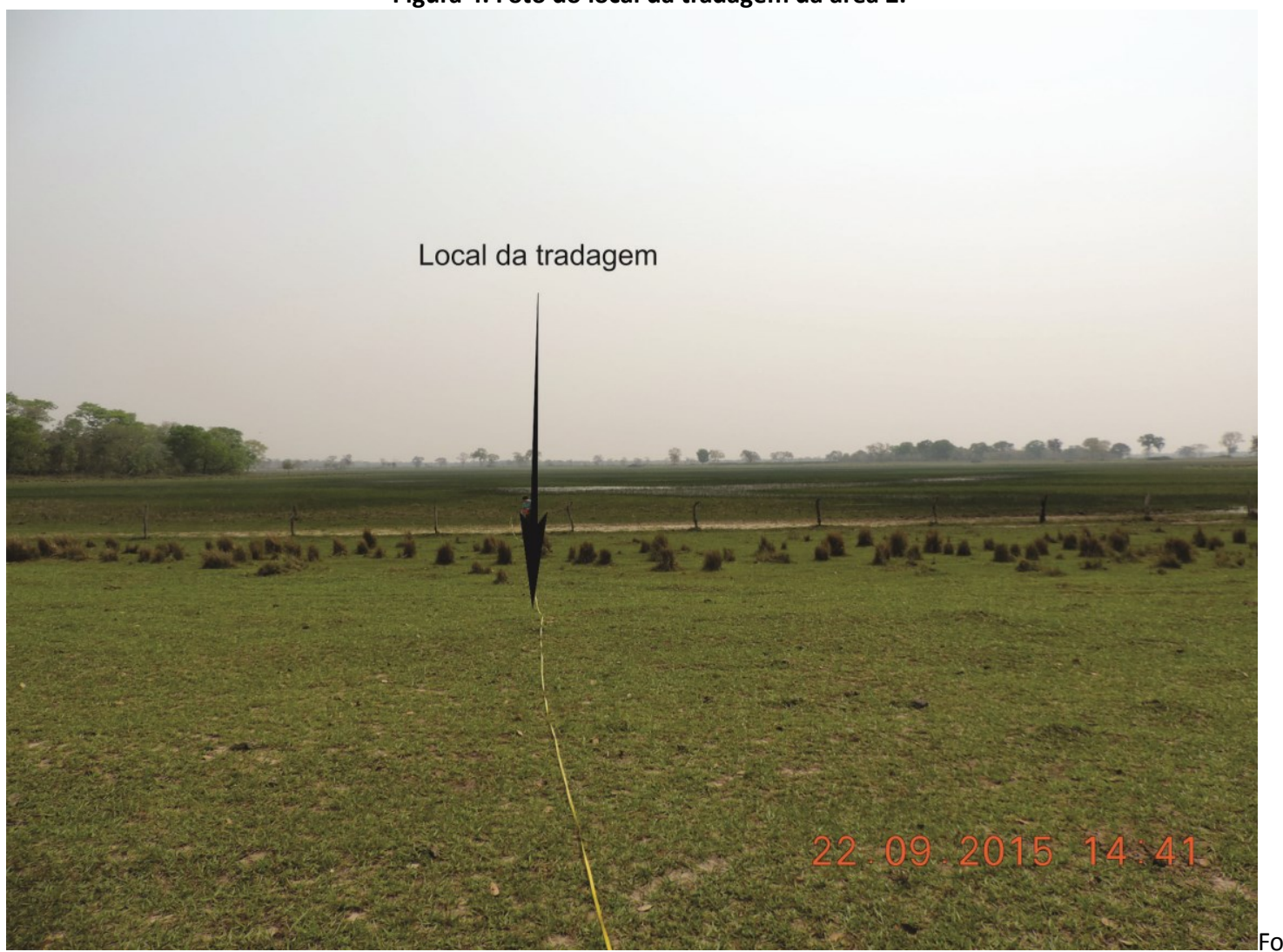

nte: Próprio autor (2015).

Na profundidade de 0 a $20 \mathrm{~cm}$ possui a coloração escura (10 YR 4/2) aparentando ser matéria orgânica em transição com a cor marrom claro (10 YR 5/3), a textura é fina, pouco úmido devido estar em contato com a superfície, em sua estrutura encontra-se raízes.

Na profundidade 0 a $40 \mathrm{~cm}$ e 40 a $60 \mathrm{~cm}$ a cor predominante é a bege (10 YR $5 / 3$ ), quanto a textura e a umidade não ocorre alterações, na estrutura surge suavemente veios amarelados (10 YR 6/8).

Em 60 a $80 \mathrm{~cm}$ a cor predominante é a mesma, marrom claro (10 YR 5/3), a textura e a não ocorre alterações, na estrutura surge suavemente veios amarelados (10 YR 6/8), ocorre um aumento significativo da umidade.

De 80 a $100 \mathrm{~cm}$ a cor de dominância continua sendo o marrom claro (10 YR 5/3), a textura não há mudanças, a estrutura ocorre o aparecimento de mosqueados amarelados (10 YR 6/8) com a presença de veios escuros (10 YR 4/2), aumento da umidade.

Na profundidade de 100 a $120 \mathrm{~cm}$ a cor predominante é o marrom claro (10 YR 5/3), a textura não muda, a estrutura continua com a presença de mosqueados amarelos (10 YR 6/8), não presença de veios escuros, mas contém material concrecionado de cor escura, a umidade aumenta.

Em amostra de 120 a $140 \mathrm{~cm}$ ocorre a transição da cor marrom claro (10 YR 5/3) para a cor amarelo (10 YR 6/8), que antes aparecia como mosqueado, a mesma textura das amostras anteriores e ocorre o aumento da umidade.

De 140 a $160 \mathrm{~cm}$ ocorre a transição da cor amarelo (10YR 6/8) para a cor marrom claro (10 YR $5 / 3)$, a textura não possui alteração e a umidade aumenta a cada profundidade. 
Na última profundidade 160 a $180 \mathrm{~cm}$ a cor predominante é a marrom claro (10 YR 5/3), suavemente volta aparecer veios amarelados (10 YR 6/8), mesma textura e presença de água livre.

A A2 apresenta uma camada fina de matéria orgânica após ocorre a transição de cores entre marrom claro e o amarelo com baixa umidade devido não existir vegetação arbustiva próximo e não estar em contato direto com água. A umidade aumenta somente quando está próximo ao lençol freático e a cor das camadas próximas possui coloração amarela.

No Histograma de A2 (Figura 5) há um agrupamento maior de grãos no diâmetro de 0,125 mm, areia fina (50\%), ou seja, maior parte dos grãos assim, o gráfico mostra que na quantidade na amostra mais próxima da superfície $(0-20 \mathrm{~cm})$ encontra-se a maior quantidade de grãos nessa malha. A segunda maior parte dos grãos encontra-se em $0,062 \mathrm{~mm}$, areia muito fina ( $35 \%)$. A terceira maior parte dos grãos encontra-se na malha $0,25 \mathrm{~mm}$, areia média ( 12\%), destacando-se a profundidade mais próxima doa superfície $(0-20 \mathrm{~cm})$, destaca-se também a malha $0,1 \mathrm{~mm}$ que detém aproximadamente $8 \%$ (argila e silte) dos grãos. Assim, têm os grãos da superfície variando entre muito fino, fino e silte e argila em grandes quantidades e a amostra mais profunda $(140-160 \mathrm{~cm})$ possui grãos variando entre muito fino e silte e argila.

Figura 5. Histograma da área 2.

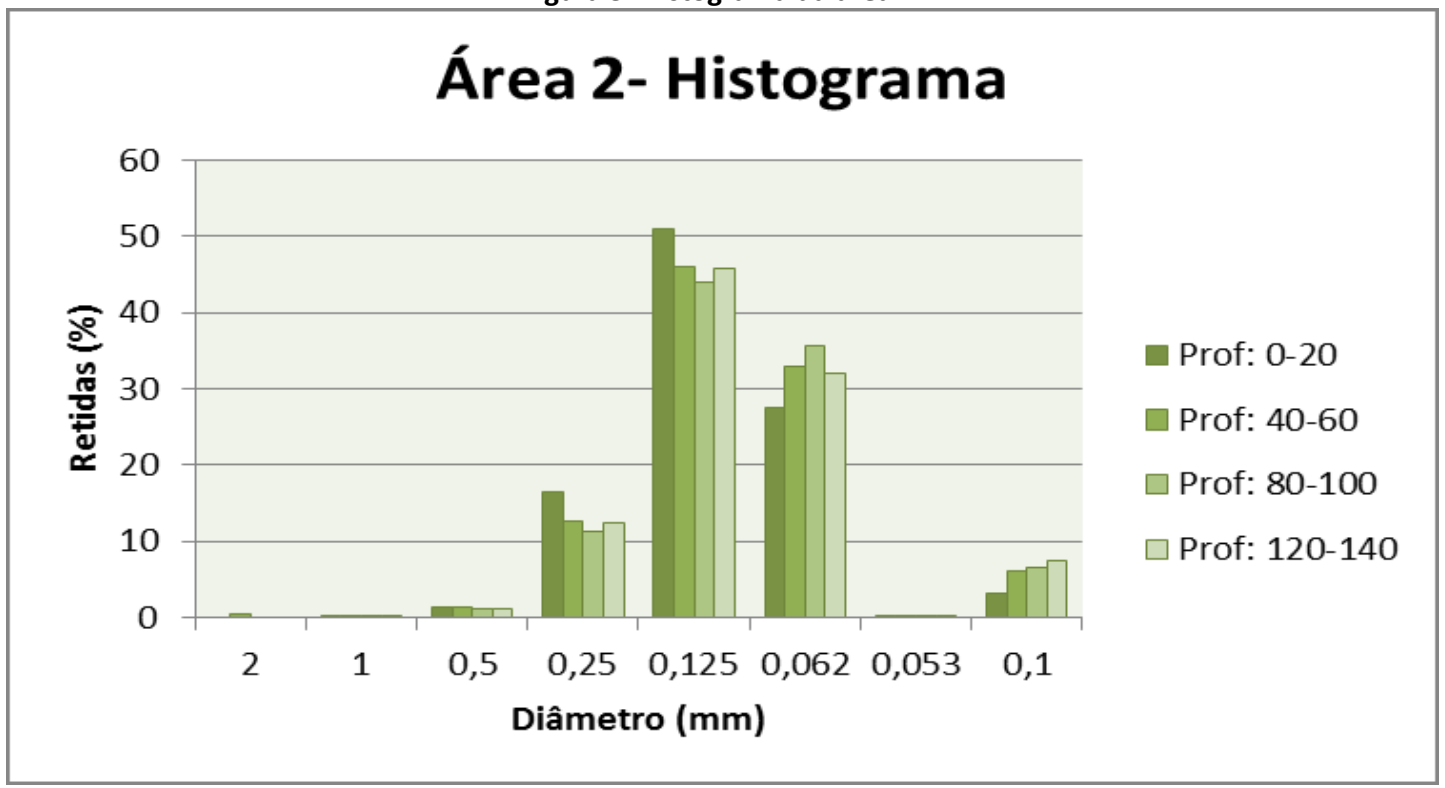

Fonte: Próprio autor (2016).

Ao comparar os dois histogramas percebem-se semelhanças quanto a quantidade de grãos nas malhas, como no diâmetro $0,125 \mathrm{~mm}$ que $\mathrm{A} 1$ e A2 possui maior concentração. O que diferencia é a quantidade de grãos retidos, pois em A1 encontra-se $60 \%$ do total da amostra diferente de A2 que possui $50 \%$. Logo, os valores das outras malhas possui a mesma coerência. No diâmetro 0,1 , possui maior quantidade em A2 enquanto em A1 é inexpressivo.

\section{CONCLUSÃO}

Após as análises dos dados obtidos percebe-se que as áreas possuem semelhanças quanto a predomínio da espessura dos grãos. A divergência é a quantidade, pois em A1 encontra-se maior quantidade de sedimentos finos e muito finos e em A2 ocorre uma variação entre fino, 
muito fino e médio. Assim, há uma quantidade considerável de grãos médios que implicam na formação das áreas.

A umidade encontrada nos dois ambientes, porém, em A1, próximo a lagoa salina, percebe-se maior influência alterando na cor e consistência das amostras. Em A2, a umidade é presente, porém tem pouca influência na cor e consistência, pois a área úmida estão em quantidades diferentes.

A camada verde encontrada em A1, que é presente na região das lagoas, se confirmou e percebe-se que é a profundidade com maior quantidade de sedimentos finos na espessura de argila e silte, justificando assim a pegajosidade encontrada na coleta das amostras. Evidenciando que quanto mais profundo os grãos tende a ser mais finos, diferente de A2 que quanto mais profundos os grãos tende a ter quantidades menores de areia fina, assim encontra-se areia fina nas amostras mais próximas da superfície.

Observam-se diferenças presentes nas duas áreas, leste e sudoeste da Nhecolândia, quanto a espessura de grãos, desse modo, devido aos estudos dessa natureza serem poucos na porção leste da Nhecolândia, e evidenciando diferenças, como as demonstradas nesse estudo, se torna importante mais levantamentos granulométricos na ótica de expandir o conhecimento acerca da relações sedimentológicas na área.

Por fim, o presente trabalho contribuiu para obter informações da região leste do Pantanal da Nhecolândia buscando compreender a dinâmica de deposição, colaborando ainda, com a conservação e o uso do Pantanal para que esse ecossistema continue sendo o mais preservado do Brasil.

\section{AGRADECIMENTOS}

Os autores agradecem a Fundação de Apoio ao Desenvolvimento do Ensino, Ciência e Tecnologia do Estado de Mato Grosso do Sul-FUNDECT pelo financiamento do projeto. Também a Universidade Federal de Mato Grosso do Sul pela concessão de bolsa de iniciação científica, infraestrutura e logística.

\section{REFERÊNCIAS BIBLIOGRÁFICAS}

$A B^{\prime} S A ́ B E R$, Aziz. Os domínios de natureza no Brasil: potencialidades paisagísticas. Ateliê Editorial: São Paulo, 2003.

ADÁMOLI, Jorge. Fitogeografia do Pantanal. In. Anais do I Simpósio Sobre Recursos Naturais e Sócio - Econômicos do Pantanal. Corumbá, 1984. EMBRAPA/UFMS: Brasília, 1986.

ANA; GEF; PNUMA; OEA, Programa de Ações estratégicas para o Gerenciamento Integrado do Pantanal e Bacia do Alto Paraguai. In: Relatório Final: Implementação de Práticas de Gerenciamento Integrado das Bacias Hidrográficas para o Pantanal e a Bacia do alto Paraguai. Desenho \& Arte Ltda: Brasília, 2004.

ALMEIDA, Fernando Flávio Marques. Geologia do Sudoeste Matogrossense. Bol. №116; Div. Geol. Min. - DNPM. 118 p. Rio de Janeiro. 1945.

ASSINE, Mario Luiz.; SOARES, Paulo Cesar. Quaternary of the Pantanal, west-central Brazil. Quaternary International, 2004. 
FRANCO, Maria do Socorro Moreira; PINHEIRO, Rui. Geomorfologia. In. Projeto RADAMBRASIL. Levantamento de recursos naturais. Folha SE 21 Corumbá e parte da Folha SE 20: Rio de Janeiro, 1982. 72.

GRADELLA, Frederico dos Santos. Morfologia do relevo da porção sul do megaleque fluvial do Taquari, Pantanal da Nhecolândia, Brasil. Universidade Estadual Paulista Júlio Mesquita Filho: Rio Claro, 2012. (Tese de doutoramento)

REZENDE FILHO, Ary Tavares; SAKAMOTO, Arnaldo Yoso. A variabilidade de salinidade do solo na área do banhado (baía/vazante) no Pantanal da Nhecolândia, MS. In. Revista eletrônica da Associação dos Geógrafos Brasileiros-Seção Três Lagoas: Três Lagoas, 2006.

SAKAMOTO, Arnaldo Yoso.; QUEIROZ NETO; José de Pereira de; FERNANDES, Erminio; CAPELLARI, Benjamin. Topografia de Lagoas Salinas e seus Entornos no Pantanal da Nhecolândia. In: II SIMPÓSIO SOBRE RECURSOS NATURAIS E SÓCIOECONÔMICOS DO PANTANAL, 1996, Corumbá. EMBRAPA, 1996.

SILVA, João Santos Vila da; ABDON, Myrian de Moura. Delimitação do Pantanal Brasileiro e suas Sub- Regiões. Pesq. Agropec. Bras., Brasília, v. 33, Numero Especial, p. 1703-1711, out. 1998.

SUGUIO, Kenitiro. Rochas sedimentares: Propriedade, Gênese, Importância econômica. Editora Edgard Blucher, 1980.

TRICART, J. El Pantanal: un ejemplo del impacto geomorfológico sobre el ambiente. Informaciones Geograficas. Chile, 1982. 